\title{
The role of origami-assisted problem posing activities in the geometric modelling of identities
}

\author{
Zuhal Ünan \\ Department of Elementary Mathematics Education, Faculty of Education, Ondokuz Mayis University, Samsun, Turkey
}

Email address:

zuhalu@omu.edu.tr

To cite this article:

Zuhal Ünan. The Role of Origami-Assisted Problem Posing Activities in the Geometric Modelling of Identities. Education Journal. Vol. 4, No. 1, 2015, pp. 1-4. doi: 10.11648/j.edu.20150401.11

\begin{abstract}
The aim of this study was to investigate the extent to which origami-assisted problem posing activities affected the ability of elementary school teacher candidates to geometrically model the basic identities $(a+b)^{2},(a-b)^{2}$, and $(a+b)(a-b)$, as well as the effect of these activities on geometric modelling. The study group consisted of 55 fourth-year teacher candidates attending a Turkish public university during the 2012-2013 academic year. The study was performed using a qualitative study model. For the qualitative data analysis, this study made use of the descriptive analysis method. Based on the study results, it was observed that instead of using representative modelling during the geometric modelling of identities, elementary school mathematics teacher candidates tended to focus on conceptual knowledge regarding the Harezmi identities, and that they performed geometric modelling based on this knowledge.
\end{abstract}

Keywords: Origami in Mathematics Education, Geometric Modelling, Identities

\section{Introduction}

Commonly defined as the art of folding paper, the word origami stems for the joining of the Japanese words ori, meaning folding, and gami, meaning paper $(1,2)$. Origami is a form of art that has captured the interest and imagination of people of all ages and cultures, and studies are currently being conducting regarding its use in education $(3,4,5,6,7)$.

Studies describe many educational benefits associated with origami. According to Boakes (3), one of the areas where origami is beneficial is mathematics. Cornelius and Tubis (8) described that origami significantly assists the development of mathematical thoughts and opinions, and contributes to the understanding of mathematical concepts. In addition, Pearl (9) described that origami allowed students to gain a better understanding of geometric shapes and principles. Cipoletti and Wilson (10) similarly described that origami enables students to improve their language skills and to develop their ability to communicate mathematically. On the other hand, Geogeson (11) expressed that establishing a good relationship between origami and mathematics is a prerequisite for mathematics education. He also described that origami represented an effective method for improving elementary students' ability to prove and demonstrate. Coad (12) described that origami is an effective tool for providing effective problem-solving skills. Wares (13), on the other hand, conducted studies that evaluated the box with the largest volume that can be obtained by following a given piece of paper.

Although current studies in the literature demonstrate the various beneficial effects of origami on students, the number of studies illustrating how students benefit from origami in mathematics-related subjects is still limited. The current study aimed to demonstrate the extent to which origami affected teacher candidates' ability to geometrically model a subject they covered during mathematics education. Within the scope of this study, the identities of $(a+b)^{2},(a-b)^{2}$ and $(a+b)(a-b)$ - which will henceforth be referred to as basic identities - were taken into consideration. We believe that the results of this study will serve as a guide for teachers and teacher candidates regarding the use of origami in the teaching of identities.

\section{Methodology}

The study was performed using a qualitative study model. The goal of qualitative studies is to obtain in-depth information instead of making generalizations, and to clearly 
and openly identify information regarding a case or individual. The intention of the current study was to observe the extent to which teacher candidates were able to model basic identities. In this context, the current study bore the characteristics of action research, which is a qualitative study method. For this reason, the data collection tools of the study consisted of open-ended questions. The action research approach is a cooperative study method that benefits individuals by encouraging them to work collectively to solve a particular problem through systematic activities. The action research approach consists of four different aspects, or sections: [1] the definition of the study questions; [2] the collection of data for the study question; [3] the analysis and interpretation of the data; [4] sharing the results with the study participants (14). Marshall and Rossman (15) described that teachers and academicians use this research approach to evaluate and renew their own teaching approaches, and to assess the effects of the new teaching approaches they might implement. In the action research approach, rather than being an objective observer or outside counselor, the researcher is directly part of the relevant community or study group. The researcher is thus directly associated with the study group; he/she consequently carries a more important role and weight in the study than those traditionally assigned to the researcher (14).

\subsection{Study Group}

The study group consisted of 55 fourth-year elementary school mathematics teacher candidates receiving education at a Turkish public university during the 2012-2013 academic year.

\subsection{Data Collection Tools}

During the study, a pre-questionnaire consisting of open-ended questions was first administered. In this pre-questionnaire, the teacher candidates were asked to geometrically model basic identities; to describe the strategy they follow during geometric modelling; and to describe their geometric drawings in detail. The pre-questionnaire thus evaluated the internal consistency of the answers they provided to these "why, what for and how?" questions. Following this, the teacher candidates were asked to participate in origami activities for three hours a week, over a period of six weeks. The intention was to allow these candidates to develop the ability to fold paper, and to geometrically interpret a model within the context of a given

problem. At the end of these activities, the candidates were requested to form the box model described in Baicker's study (16) through folding. The folded box model was then opened, and the number of folding lines was evaluated. By taking the box they folded into consideration, the teacher candidates were asked to write and discuss problems involving proposals such as "If $a^{2}$ is a square, then ... will be obtained". The different directions taken in the folding/shaping of the boxes led to the posing of different types of problems. When the teacher candidates expressed these problems algebraically, basic identities were obtained. The point that must be mentioned here is that although the teacher candidates posed very different types of problems, the algebraic expression provided by the candidates for these problems remained limited to basic identities. The students thus worked in an environment which, instead of allowing them to acquire new information, provided them the opportunity to critically view and assess their current knowledge. Following this activity, the students were administered with the main study questionnaire. Similar to the pre-questionnaire, the final questionnaire also asked the students to geometrically model basic identities; to describe the strategy they follow during geometric modelling; and to describe their geometric drawings in detail. As a final step, the data collected by the pre-questionnaire and the final questionnaire were compared.

\subsection{Data Analysis and Interpretation}

For qualitative data analysis purposes, this study employed the descriptive analysis method. The study data were organized according to the themes identified by the study questions (17). A pre-questionnaire was administered prior to the origami activity to determine the initial knowledge of the students. In this process, the forms completed by the teacher candidates were first numbered, and then merged under common themes following the detailed evaluation of each form. The common themes that were identified were then tabulated according to their frequency. To increase the reliability of the study, the common themes were also separately evaluated by two academicians specializing in the field. The issues identified by these academicians were solved, and an agreement was reached with regards to the content of the common themes.

\section{Results}

Table 1. Pre-questionnaire results regarding the geometric modelling of identities

\begin{tabular}{|c|c|c|c|c|c|c|}
\hline \multirow[t]{2}{*}{ Modelling of basic identities } & \multicolumn{2}{|c|}{$\begin{array}{l}\text { Modelling of the }(a+b)^{2} \\
\text { identity }\end{array}$} & \multicolumn{2}{|c|}{$\begin{array}{l}\text { Modelling of the (a-b) } \\
\text { identity }\end{array}$} & \multicolumn{2}{|c|}{$\begin{array}{l}\text { Modelling of the }(a-b)(a+b) \\
\text { identity }\end{array}$} \\
\hline & $N=55$ & $\%$ & $N=55$ & $\%$ & $\mathbf{N}=\mathbf{5 5}$ & $\%$ \\
\hline $\begin{array}{l}\text { Students who performed modeling by taking the } \\
A^{2} \text { area into account }\end{array}$ & 7 & 12.7 & 27 & 49.1 & 8 & 14.6 \\
\hline $\begin{array}{l}\text { Students who performed modeling by taking into } \\
\text { account squares or rectangles whose side lengths } \\
\text { were given }\end{array}$ & 36 & 65.5 & 10 & 18.2 & 28 & 50.9 \\
\hline $\begin{array}{l}\text { Students who performed modeling by taking the } \\
\text { identity of the given expression }\end{array}$ & 9 & 16.4 & 14 & 25.4 & 13 & 23.6 \\
\hline Blank & 3 & 5.4 & 4 & 7.3 & 6 & 10.9 \\
\hline
\end{tabular}


Table 2. Final questionnaire results regarding the geometric modelling of basic identities

\begin{tabular}{|c|c|c|c|c|c|c|}
\hline \multirow{2}{*}{ Modelling of basic identities } & \multicolumn{2}{|c|}{$\begin{array}{l}\text { Modelling of the }(a+b)^{2} \\
\text { identity }\end{array}$} & \multicolumn{2}{|c|}{$\begin{array}{l}\text { Modelling of the (a-b) } \\
\text { identity }\end{array}$} & \multicolumn{2}{|c|}{ Modelling of the $(a-b)(a+b)$ identity } \\
\hline & $\mathbf{N}=\mathbf{5 5}$ & $\%$ & $\mathbf{N}=\mathbf{5 5}$ & $\%$ & $\mathbf{N}=\mathbf{5 5}$ & $\%$ \\
\hline $\begin{array}{l}\text { Students who performed modeling by taking } \\
\text { the } \mathrm{A}^{2} \text { area into account }\end{array}$ & 48 & 87.3 & 52 & 94.5 & 46 & 83.7 \\
\hline $\begin{array}{l}\text { Students who performed modeling by taking } \\
\text { into account squares or rectangles whose side } \\
\text { lengths were given }\end{array}$ & 5 & 9.1 & 0 & 0 & 3 & 5.4 \\
\hline $\begin{array}{l}\text { Students who performed modeling by taking } \\
\text { the identity of the given expression }\end{array}$ & 2 & 3.6 & 3 & 5.5 & 6 & 10.9 \\
\hline
\end{tabular}

The students were asked to describe the geometrical modelling of the $(a+b)^{2},(a-b)^{2}$, and $(a-b)(a+b)$ identities, the strategy they used in their geometric modelling, and the models they developed. The calculated percentages and frequencies for the answers provided by the students to the pre-questionnaire and the final questionnaire are provided in Table 1 and Table 2.

Geometric modelling of the $(a+b)^{2}$ identity: In the pre-questionnaire, $65.5 \%$ of the teacher candidates divided the square that had a side length of $(a+b)$ into smaller components/blocks, and wrote the square's area as the total area of these components/blocks. The ratio of teacher candidates who followed the same approach was $9.1 \%$ in the final questionnaire. While $16.4 \%$ of the candidates performed modelling during the pre-questionnaire by taking the identical of the given expression, this ratio was determined as $3.6 \%$ in the final questionnaire. In this activity, the candidates were able to obtain the desired identity by bringing together as many blocks as they needed (similar to what is done with algebraic blocks). An evaluation of the written documents indicated that in this activity, rather than seeing the problem as the change in a square, the candidates modelled the problems as the whole set of pieces in the identity's expansion. While only $12.7 \%$ of the candidates considered the identity as the change in the area of $\mathrm{a}^{2}$, this ratio increased to $87.3 \%$ in the final questionnaire. The teacher candidate coded as $\mathrm{O}_{50}$ gave the following description in the pre-questionnaire: "We divided a square with a side length of $(a+b)$ into a square, rectangle, and square with the areas of $a^{2}, a b$, and $b^{2}$, respectively. This gave us the identity we desired". However, in the final questionnaire, the same teacher candidate provided the following description: "We take a square with an area of $a^{2}$. If we form another square by increasing the side lengths of this original square by an amount $b$, the area of the new square will be $(a+b)^{2}$ ".

Geometric modelling of the $(a-b)^{2}$ identity: The ratio of teacher candidates who performed modelling in the pre-questionnaire by taking into account the identity of the expression was $25.4 \%$, while the ratio of candidates who did so in the final questionnaire decreased to $5.5 \%$. The candidates attempted to reach the expression $(a-b)^{2}$ through algorithmic calculations by starting from $\mathrm{a}^{2}-2 \mathrm{ab}+\mathrm{b}^{2}$, the algebraic identical of the given expression. Although the given identity could be modelled algebraically, the candidates were not able to model it geometrically. In the pre-questionnaire, $18.2 \%$ of the candidates defined the (a-b) length (including $a>b$ ), and attempted to directly obtain a square of this length. None of the candidates followed this approach in the final questionnaire. It was observed that $49.1 \%$ of the candidates reflected the problem as a change in the area of $\mathrm{a}^{2}$, while the ratio of candidates who did so in the final questionnaire was $94.5 \%$. The teacher candidate coded as $\mathrm{O}_{44}$ used the following approach in the modelling he performed in the pre-questionnaire: "If we remove two pieces in the $a b$ area and one piece from the $b^{2}$ area of our shape with $a$ total area of $a^{2}$, then we can obtain an area of $(a-b)^{2}$ ". On the other hand, in the final questionnaire, the same teacher candidate used the following modelling approach: "Harezmi also showed identities in a similar way. That is why I followed this approach. First, I formed an area $a^{2}$, then I removed pieces of length $b$ from the sides with length a. After I deducted from $a^{2}$ the total area of the removed pieces, I obtained an area of $(a-b)^{2, "}$.

Geometric modelling of the $(a+b)(a-b)$ identity: Although the ratio of teacher candidates who obtained the expression $(a+b)(a-b)$ by forming rectangles of certain side lengths was $50.9 \%$ in the pre-questionnaire, this approach did not utilize the identical expression $a^{2}-b^{2}$ during geometric modelling of the identity.

In the final questionnaire, the ratio of candidates who used this approach decreased to $5.4 \%$. It was observed that $23.6 \%$ of the candidates modelled the identity by subtracting the area $\mathrm{b}^{2}$ from a corner of an area $\mathrm{a}^{2}$. In the post-questionnaire, $10.9 \%$ of candidates employed the same modelling approach. While only $14.6 \%$ of the students interpreted the identity as the change in the area of $\mathrm{a}^{2}$, this ratio increased to $87.3 \%$ in the final questionnaire. In this context, the candidates pictured an area of $\mathrm{a}^{2}$, and then increased the length of one side on this area by an amount $b$, while decreasing the length of another side by an amount $b$. The $(a+b)(a-b)$ was thus obtained, which the candidates interpreted according to the area $\mathrm{a}^{2}$. The teacher candidate coded as $\mathrm{O}_{55}$ used the following approach in the modelling he performed in the pre-questionnaire: "Using the lengths $a$ and $b$, we obtain the pieces $(a-b)$ and $(a+b)$. These lengths are added to one another at right angles, which will then give us an area". In the final questionnaire, the same teacher candidate used the following modelling approach: "We took an area of $a^{2}$. We increased the length of side a by an amount $b$. We then increased the length of the other side a by an amount $b$. If we carry the area $b(a-b)$ below, then $b^{2}$ will remain open". 
In the general, the candidates formed their modelling strategies in the pre-questionnaire according to the identity that was provided. These strategies involved the writing of a total area as the total of separate areas; the use of the algebraic squares approach; the forming of geometric lengths; and the writing of algebraic expressions. In the final questionnaire, $83 \%$ of the teacher candidates considered the three relevant identities as changes in area $\mathrm{a}^{2}$, and developed their strategy accordingly. The change in question was modelled based on the corresponding changes in two parameters, involving either a simultaneous increase or decrease in the side length of a given square, or as an increase in one of the side lengths while the other decreases.

\section{Discussion and Conclusions}

In the study conducted by Pope (5), it was determined that origami taught students the fact that each problem or question does not have a single correct answer. In our study, it was observed that the teacher candidates developed different and alternative solutions to solve a given problem. Another important observation of our study was that the proper identification and understanding of the problem accompanying the origami activity allowed candidates to develop their conceptual knowledge of the relevant subject. In the study conducted by Boakes (4), it was determined that origami was as effective as traditional teaching methods in the teaching and understanding of geometric terms and concepts. In our study, we observed that origami allowed students to become more effective and successful in interpreting geometric terms and concepts, and also in converting them to algebraic expressions. It was also noted that following the origami activities, the teacher candidates were able to make better use of the mathematical language. In addition, the candidates were better able to identify and pose problems suitable for a particular hypothesis.

In this study, the teacher candidates used origami and folded paper to form geometric shapes in accordance with the models they developed and to find solutions. Doing so required them to review and reconsider their current mathematical knowledge, to restructure the relevant elements of their mathematical knowledge as necessary, and to form their own mathematical approaches. In this respect, the observations of our study were parallel with Boaler's study (18). The study of Roh (19) described that learning based on problem-posing allows students to develop their own approaches and methods towards a particular case/problem, and to also jointly use and combine their practical and conceptual knowledge. In our study, the origami-assisted problem posing activities allowed the teacher candidates to formulate their own problems and to make associations with the relevant mathematical concepts. Such activities allowed students to better solve problems, and to better understand practical and conceptual knowledge by avoiding confusions between the two.

\section{References}

[1] J.L. Krier, Mathematics and Origami: The Ancient Arts Unite, 2007.

[2] R. Beech, The practical illustrated encyclopedia of origami: The complete guide to the art of paper folding, London: Lorenz Books, 2009.

[3] N.J. Boakes, "Origami-mathematics lessons: Paper folding as a teaching tool", Mathidues, 2008, 1(1), 1-9.

[4] N.J. Boakes, "Origami instruction in the middle school mathematics classroom: Its impact on spatial visualization and geometry knowledge of students", Research in Middle Level Education Online, 2009, 32(7), 1-12.

[5] S. Pope, "The Use of Origami in the Teaching of Geometry", Proceedings of the British Society for Research into Learning Mathematics, 2002, 22(3), 67-73.

[6] K. Chen, "Math in motion: Origami math for students who are deaf and hard of hearing", Journal of Deaf Studies and Deaf Education, 2006, 11(2), 262-266.

[7] S. Sze, Math and mind mapping: Origami construction. Dunleavy: Niagara University, 2005 [ERIC Document Reproduction Service No. ED490352].

[8] V. Cornelius and A. Tubis, "On the effective use of origami in the mathematics classroom", Paper presented at the fourth International Conference on Origami in Science, Mathematics and Education (4OSME), Pasedena, CA, 2006.

[9] B. Pearl, Math in motion: Origami in the classroom (k-8), Langhorne, PA: Math in Motion, Incorporated, 1994.

[10] B. Cipoletti and N. Wilson, "Turning origami into the language of mathematics", Mathematics Teaching in the Middle School, 2004, 10(1), 26-31.

[11] J. Georgeson, "Fold in origami and unfold math", Mathematics Teaching in Middle School, 2011, 16(6), 354-361.

[12] L. Coad, "Paper folding in the middle school classroom and beyond", Australian Mathematics Teacher, 2006, 62(1), 6-13.

[13] A. Wares, "Using origami boxes to explore concepts of geometry and calculus", International Journal of Mathematical Education in Science and Technology, 2011, 42(2), 264-272.

[14] B.L .Berg, Qualitavite research methods for the social sciences. Boston: Allyn and Bacon, 2001.

[15] C. Marshall and G.B. Rossman, Designing qualitative research (3rd. Ed.), Thousand Oaks, CA: Sage Publications, Inc., 1999.

[16] K. Baicker, Origami Math, Grades 4-6.Scholastic, 2004.

[17] M. Miles and A.M. Huberman, Qualitative data analysis: an expanded sourcebook, Thousand Oaks, CA: Sage, 1994.

[18] J. Boaler, "Open and closed mathematics: student experiences and understandings", Journal for Research on Mathematics Education, 1998, 29(1), 41-62.

[19] K.H.Roh, Problem Based Learning in mathematics. Clearing for secience, mathematics and environmental Education, (2003) 